\title{
Fontes históricas na sala de aula: uma possibilidade de produção de conhecimento histórico escolar?
}

Flávia Eloisa Caimi*

Resumo: A incorporação e a utilização de fontes históricas nas aulas de história constituem pauta dos debates acadêmicos e escolares atuais, nos quais se discute acerca das suas possibilidades como elemento de superação do conteudismo/ verbalismo e das suas potencialidades como instrumento de produção de conhecimento histórico na educação básica. E ste estudo apresenta a problematização do tema, identificando nos antigos manuais escolares enos atuais livros didáticos, bem como nas políticas públicas instauradas pelos Parâmetros Curriculares N acionais (PCN s) eno Programa $\mathrm{N}$ acional do Livro Didático (PN LD ), os usos propostos e efetivados de fontes como alternativa para a produção de conhecimento histórico no âmbito do ensino da história escolar, reconhecendo mudanças e permanências ali manifestadas.

Palavras-chave: E nsino de história. Fonte histórica. Produção de conhecimento.

O tratamento do tema "fontes históricas na sala de aula" remete, inexoravelmente, ao estabelecimento de relações com as atuais discussões historiográficas, porque a história, como disciplina escolar, ainda que possua especificidades e finalidades que thes são próprias, não prescinde de um estreito diálogo com a ciência

* Professora Titular no Curso de H istória da Universidade de Passo Fundo/ RS. D outora em E ducação pela U niversidade Federal do Rio G rande do Sul. E -mail: caimi@upf.br 
de referência - no caso a história acadêmica - e com os princípios, fundamentos e métodos que regem a pesquisa histórica. Tal entendimento não significa decretar a dependência da história escolar em relação ao conhecimento acadêmico, tampouco tomá-la como um saber inferior na hierarquia de conhecimentos, mera vulgarização didática de um corpo de saberes produzido pelos "cientistas". Sem entrar no polêmico debate que permeia este tema, é preciso admitir que os dois campos - escolar e acadêmico - são portadores de dinâmicas próprias, as quais se relacionam com inúmeras instâncias e dimensões, de acordo com as finalidades e especificidades de sua atuação, razão pela qual este estudo inicia adentrando no debate historiográfico.

$\mathrm{N}$ a E uropa do século XIX, estabeleceu-se um importante marco nos estudos históricos, pois foi o momento em que se constituíram as bases científicas para a história, bem como para diversas outras áreas do conhecimento. No campo da história, foram ali constituídos dois paradigmas com predominante influência na investigação historiográfica ao longo de décadas: a história como a ciência da reconstituição do passado e o documento impresso e/ ou manuscrito como fonte privilegiada das informações a serem obtidas.

A repercussão desse debate no Brasil ensejou a criação, em 1838, do Instituto H istórico e G eográfico Brasileiro e, no mesmo ano, do Colégio Pedro II, no Rio de Janeiro. D entre suas finalidades, estão, respectivamente, a produção e a disseminação da história nacional, que resultaram na configuração de uma história pátria cuja função pedagógica de "mestra da vida" exerceu o papel de orientadora dos jovens para a civilidade e o patriotismo ao longo de muitas décadas. A demais, segundo José H onório Rodrigues (1982, p. 37), o IHG B cumpriu relevante papel ao "coligir, metodizar, publicar ou arquivar os documentos necessários para a $\mathrm{H}$ istória e $\mathrm{G}$ eografia do Império do Brasil", ainda que tais publicações permanecessem limitadas à coleta e ao registro de dados, carecendo de análises mais abrangentes e originais, como atestam as edições da sua revista, dadas a conhecer a partir de 1839. 
$N$ as primeiras décadas do século $X X$, assistimos a um conjunto de transformações de ordem política, econômica e sociocultural, que vão desde o esgotamento e ruptura do quadro monárquicoescravocrata até a fundação de universidades em grandes centros e a criação das faculdades de filosofia e ciências humanas, abrigando os primeiros cursos de história. N eles, não só podemos reconhecer 0 aumento da profissionalização dos historiadores, como também o esforço de produzir conhecimentos acerca da constituição da nação e da formação da sociedade brasileira. Para Samara e Tupy (2007, p. 33), desde então, o estudo da história no Brasil, acompanhando os debates internacionais no campo da metodologia e teorias, "negaria ensaios interpretativos, se distanciaria dos estudos genealógicos e passaria a obedecer a critérios científicos de pesquisa documental". A utores como O liveira Vianna, G ilberto F reyre, Sérgio Buarque de H olanda, Caio Prado Júnior, dentre outros, estando na academia ou fora dela, protagonizaram estudos vinculados à história social e econômica e, ainda, "permitiram a discussão da teoria da história, de seus métodos e técnicas de pesquisa", abrindo assim "um amplo leque deoportunidades para o trabalho com o documento" (SAM ARA; TUPY, 2007, p. 41).

E m época mais recente, notadamentea partir da década de 1970 , verificamos nova reorientação da pesquisa histórica no Brasil, estimulada especialmente pelas transformações contextuais do cenário político-social e pela acentuada proliferação dos cursos de graduação e pós-graduação na área da história. Podemos sumarizá-las em torno de alguns pontos, a saber: a) 0 esgotamento dos esquemas explicativos sustentados nas grandes sínteses; b) a incorporação de novos temas e objetos de pesquisa, alicerçados em estudos de gênero (mulheres, educação feminina, prostituição, práticas afetivas), estudos étnicoculturais (indígenas, afrodescendentes, mestiçagem) e conjuntos temáticos (casamento, família, crianças, festas, rituais); c) a ampliação das pesquisas em temas regionais, que favorecem revisionismos das tradicionais explicações globais; d) uma nova classificação e tratamento das fontes, com 0 emprego de processos criminais e 
eclesiásticos, devassas e testamentos, imprensa, história oral, além do uso de fontes iconográficas e audiovisuais; e) visão multidisciplinar da história, ocasionando o diálogo com inúmeras áreas, como a demografia, a economia, a antropologia, a etnografia, a sociologia, a ciência política, a literatura, dentre outras (FICO, 2000; G 0 MES, 2000).

m

N o campo do ensino de história, as transformações também são contundentes eas proposições não são menos ambiciosas, como verificamos no seguinte elenco: a) a compreensão da relatividade do conhecimento histórico, fruto não de verdades definitivas, mas do olhar do historiador - sempre seletivo -, do método e das fontes; b) ruptura com a ordenação temporal e espacial dos conteúdos, fundamentada na noção de múltiplas temporalidades, de Fernand Braudel (1978), e na perspectiva francesa da história por eixos temáticos; c) consenso em torno da impossibilidade de estudar toda a história da humanidade, de todas as épocas e lugares, e da necessidade de fazer recortes de temáticas e problemáticas de estudo nos programas escolares, com base em preocupações advindas das práticas sociais e das problemáticas do tempo presente; d) compreensão da memória histórica como instrumento de luta, de emancipação e de transformação social, na medida em contribui para o desenvolvimento de habilidades de pensamento que permitem a desnaturalização do passado e o questionamento das tradições herdadas; e) incorporação de diversas linguagens de ensino, com especial atenção para o cinema, a música, a imagem e documentos históricos impressos em geral; f) tentativa de substituição da memorização pela reflexão histórica, favorecendo a aprendizagem pela descoberta e pela construção do conhecimento; g) ênfase na produção do conhecimento pelo manuseio de fontes históricas, visitações a arquivos, museus, sítios arqueológicos, destacando-se o esforço de promover a apropriação dos procedimentos da pesquisa histórica, pelos estudantes; h) valorização da história local pelo estudo do meio e pela memória oral (CAIMI, 2008). 
D iante do exposto, infere-se que as propostas relativas ao ensino de história esboçadas nos últimos anos estão afinadas com os debates de renovação da historiografia e da pesquisa histórica. Tanto as linhas de força que emergem no campo investigativo quanto as propostas que permeiam o saber histórico escolar representam indicativos de ruptura com concepções educacionais e historiográficas que foram predominantes nas universidades e escolas brasileiras durante décadas. $\mathrm{N}$ a seqüência do estudo, serão focalizados dois momentos distintos do ensino da história escolar brasileira, buscando-se reconhecer como se deram as transformações metodológicas no tratamento de fontes históricas para uso escolar, primeiramente, em manuais didáticos e livros de história editados nos primeiros anos da Repúblicae, posteriormente, na produção historiográficaatual.

\section{A história escolar na Primeira República: os manuais didáticos no contexto do escolanovismo}

O s manuais didáticos adotados nas escolas brasileiras até a primeira década do século XX eram editados e impressos no exterior, especialmente em Portugal e na França, sendo também escritos por autores estrangeiros. N os anos iniciais da República, as obras nacionais começaram a ser editadas, marcadas por um forte apelo moral, tomando a história, os grandes feitos e seus protagonistas como exemplos de vida para a formação da sociedade e para a construção da nação.

N ão se pode afirmar a rigor que, nos primórdios da República, 0 ensino de história tenha se alterado substancialmente no que se refere às concepções teórico-historiográficas predominantes desde a época do I mpério, solidamente sustentadas em métodos verbalistas e livrescos. N ota-se, no entanto, uma preocupação mais evidente com os métodos empregados no campo da história escolar. E studos como os de Mattos (2000) e Fonseca (2003) demonstram que a recepção do movimento da Escola N ova na educação brasileira 
influenciou significativamente 0 ensino da história, fazendo emergir outras possibilidades metodológicas, que procuravam superar, ao menos no ideário acadêmico, as práticas memorísticas de aprendizagem histórica.

E ssa influência é demonstrada nos manuais didáticos e nas obras dirigidas especialmente aos professores, contendo orientações em termos de métodos e recursos mais apropriados para atingir os objetivos da disciplina. Podemos referir o caso de Jonathas Serrano, autor de inúmeros livros e manuais didáticos de história nas primeiras décadas da República, ${ }_{1}^{1}$ caracterizado como um escolanovista católico, preocupado com o uso de novas tecnologias no ensino da história escolar, especialmente mapas, imagens e o cinema como recursos didáticos. Serrano foi professor do Colégio Pedro II e da Escola N ormal do D istrito Federal, membro da diretoria do IH G B, subdiretor técnico da Instrução no Rio de Janeiro na época da administração deFernando de Azevedo e, em seguida, nomeado membro do ConseIho N acional de E ducação.

$N$ a década de 1930, esse autor publicou uma obra sob o título E scola N ova, na qual declarava que "o movimento renovador da escola, a cruzada pela escola nova pode e deve continuar (continuar e não começar, pois foi brilhantemente iniciado faz algum tempo), e com a colaboração de todas as forças vivas do nosso meio" (SE RRAN 0, 1932, p. 115). E m outra obra, publicada entre 1912 e 1913, intitulada E pítome de história universal, Jonathas Serrano já formalizava uma proposta pedagógica para o ensino da história escolar, defendendo os princípios da pedagogia científica em voga na época, como se verifica neste trecho:

N ão élícito em nossos dias, graças ao progresso da pedagogia científica, seguir os velhos e condenáveis processos exaustivos da memória, em que se decoravam páginas e páginas, fazendo-se da história uma insuportável nomenclatura recheada de uma fatigante cronologia (...). M artírio da memória, o que deverá ser encanto da imaginação! G raças ao cinematógrafo, 
as ressurreições históricas não são mais uma utopia. 0 curso ideal fora uma série de projeções bem coordenadas, o cinema a serviço da história, imenso gáudio e lucro incalculável dos alunos. Isto, porém, é por enquanto ainda bem difícil. Resta, entretanto, mais modestamente, o emprego das gravuras, retratos, mapas, etc., para ensinar pelos olhos e não apenas, e enfadonhamente não raro, só pelos ouvidos, em massudas, monótonas e indigestas preleções (SE RRA N 0, 1937, p. 13).

$\mathrm{N}$ as entrelinhas do texto deSerrano, podemos identificar pressupostos didático-metodológicos renovadores. Segundo Schmidt (2004, p. 193), Serrano buscara em John D ewey os referenciais básicos para formalizar uma proposta quanto ao papel, ao significado e à metodologia da história escolar. Seguindo o ideário escolanovista, a principal referência do ensino de H istória seria "a experiência da criança, o estímulo à sua curiosidade e o desenvolvimento de significações com base nas necessidades reais das crianças, tendo como ponto de partida a relação passado/ presente".

O utro caso exemplar, que reúne características da história cívico-patriótica - predominante numa época em que o país precisava fortalecer o E stado-N ação - , com o novo ideário metodológico, é o conhecido livro de Rocha Pombo (1857-1933) intitulado N 0ssa Pátria, que, tendo sido escrito em 1917, chegou à 88ạ edição na década de 1970, totalizando cerca de 450 mil exemplares impressos. Seu autor, José F rancisco da Rocha Pombo, um paranaense de M orretes, participou ativamente da vida política do país: formado bacharel em Ciências Jurídicas e Sociais pela Faculdade de D ireito do Rio de Janeiro, exerceu funções de jornalista, professor, poeta e historiador; fundou e dirigiu um jornal em Curitiba, no qual fez campanhas abolicionista e republicana; foi deputado federal provincial (1886); professor do Colégio Pedro II; sócio efetivo do IH GB e membro eleito da A cademia Brasileira de Letras, embora falecesse antes de tomar posse.

N o prefácio de N 0ssa Pátria, Rocha Pombo apresenta sua obra nos seguintes termos: 
Fontes históricas na sala de aula...

Ê ste livrinho é feito para a inteligência das crianças e dos homens simples do povo. N estes dias, que alvorecem tão novos, em que se procura criar o culto da pátria, penso que o primeiro trabalho para isso é fazer a pátria conhecida daqueles que a devem amar. $\mathrm{N}$ ão se ama uma terra senão quando alguma coisa sagrada a ela nos prende - algum sacrifício, ou alguma tradição gloriosa. São essas coisas que firmam a nossa existência moral. Sentir o que fizeram de grande os nossos antepassados equivale a tomar o compromisso de os continuar na história. O s nossos anais, conquanto sejamos novos no mundo, registam lances de que nos podemos orgulhar. Fixá-los, em suas linhas gerais, na alma de gerações, é, pois, o processo mais prático e seguro de nela criar e nutrir 0 sentimento de pátria. É o que procuro aqui fazer com todo carinho. 0 utros poderão fazer coisa melhor, com mais talento, mas eu escrevi este livrinho com todo meu coração. Rio-1917 (POM BO, s/ d, p. 3).

A capa do livro é reveladora de suas intenções, pois apresenta gravura de um casal de crianças segurando, talvez admirando, a bandeira do Brasil. A baixo da gravura, aparece o nome da obra, seguida da seguinte inscrição: "narração dos fatos da história do Brasil, através da sua evolução com muitas gravuras explicativas". Vejamos:

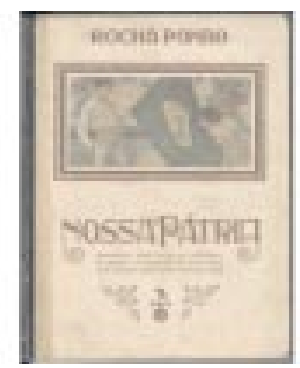

O rganizado em cinqüenta e uma lições (pontos), que iniciam com o tema "N ossa Pátria" e encerram com o ponto "O que é hoje 0 Brasil", o livro totaliza 169 páginas e tem dimensões de $13 \mathrm{~cm}$ de 
largura por $18 \mathrm{~cm}$ de altura, tratando-se realmente de "um livrinho", como caracteriza o próprio autor. A partir da página 155, são apresentados cinco quadros sinópticos, representativos dos "cinco séculos da nossa história", demonstrando que nada havia em terras sul-americanas antes de 1500. Tratando-se de um livro de leitura, não contém indicação de atividades.

0 que importa destacar aqui é a ênfase dada às imagens, própria do espírito pedagógico da época. As 51 lições são permeadas por um conjunto de 149 gravuras, distribuídas em: a) 63 personagens ilustres da pátria brasileira ou de Portugal, a maioria políticos, mas também al guns intelectuais, poetas e literatos, como L uís de Camões, $\mathrm{G}$ regório de Mattos, José de A lencar, Varnhagen etc.; b) 56 ilustrações de obras artísticas, como as de Calixto, Pedro A mérico, Victor M eirelles, D ebret, Rugendas, dentre outros, e imagens de vistas como a E stação da Luz, em São Paulo, a E nseada de Botafogo nos primeiros tempos da colônia, a Bahia há um século etc.; c) 16 imagens de monumentos e edifícios, incluindo estatuária com nomes ilustres, como Cabral, Anchieta, Bonifácio, Tiradentes, dom Pedro I, duque de Caxias e outros; d) três mapas, sendo o primeiro mundial com a América ao centro, o segundo da península I bérica e o terceiro da Província Cisplatina; e) onze imagens diversas, contemplando a bandeira nacional, as armas da República, caravela, bússola, artefatos indígenas, dentre outros objetos. Cumpre registrar que os três mapas são coloridos, havendo mais seis imagens coloridas no livro, todas relacionadas à pátria: bandeiras, laço nacional e folha da independência.

É de destacar que, no que concerne às imagens apresentadas no livro de Rocha Pombo, não percebemos preocupações em contextualizá-las no texto, tampouco em identificar sua produção, tanto que não há quaisquer referências sobre autores, títulos, datas, créditos, legendas, etc. Também nas representações cartográficas não há indicações de convenções, estando ausentes aspectos como fonte, orientação, escala etc. Todas essas ausências permitem-nos inferir que a incorporação de fontes nos manuais didáticos desta época cumpre uma função ilustrativa, tal como propugnava Serrano 
(1932), trazendo apenas a modesta possibilidade de ensinar pelos olhos, não só pelos ouvidos. Não está colocada, ainda, a intenção de tomar essas fontes como objetos de estudo, desvendando suas condições de produção, nem mesmo a possibilidade de, por meio de seu estudo, desenvolver determinadas competências cognitivas, como observação, investigação, compreensão, interpretação, argumentação, análise, síntese, comparação, formulação de hipóteses, crítica documental, etc. A centralidade da proposta está no conteúdo e na sua ilustração, bem como no propósito de despertar 0 amor à pátria e 0 culto aos seus personagens e feitos.

Continuando a perscrutação da presença de fontes históricas nos manuais didáticos antigos, identificamos a incorporação de outras tipologias, tais como trechos de leitura de obras acadêmicas e documentos impressos. E ditado na metade da década de 1950 pela FTD, de acordo com a Portaria Ministerial no 966, de 2/ 10/ 1951, para a primeira série ginasial, o manual escrito por João Pereira V itória e Florentino A dami apresenta um fac-símile da última página da carta de Pero Vaz de Caminha, seguida de "tradução" feita por Jaime Cortesão (1955, p. 28). N a página anterior, consta a tela $D$ escobrimento do B rasil, de 0 scar Pereira da Silva, sem qualquer outra referência que não o nome do autor e o título da obra. Vejamos o fac-símile da carta:

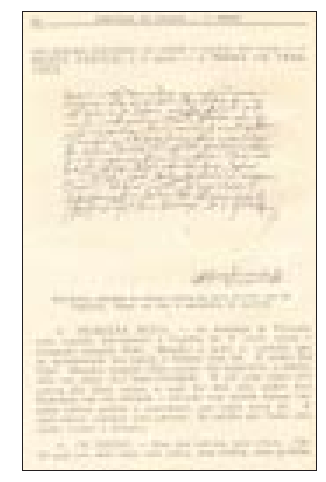

E m diversos capítulos da obra, os autores apresentam trechos de leitura de escritores consagrados, geralmente nacionais, para 
complementar e/ ou comprovar as idéias apresentadas no texto didático, como podemos observar na seqüência (1955, p. 78-9):

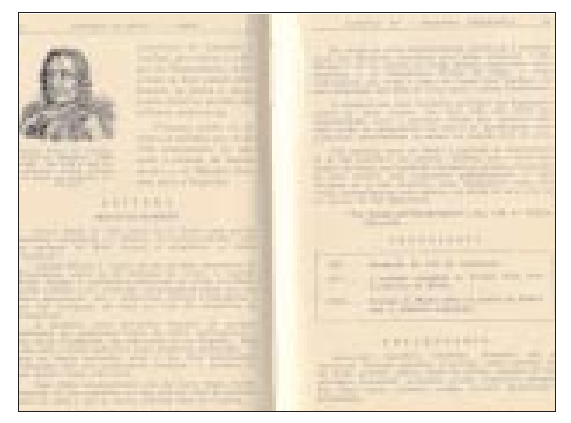

N este caso, trata-se de trecho do livro $\mathrm{N}$ o tempo dos bandeirantes (1939), de Belmonte (1896-1947), conhecido jornalista e caricaturista, criador da popular figura de "Juca Pato". N a seqüência do trecho, constam uma cronologia e um vocabulário sobre o tema do capítulo, sem, contudo, haver qualquer proposta metodológica para 0 estudante interagir com 0 texto de Belmonte. M ais uma vez, portanto, o caráter da fonte é ilustrativo.

E $m$ que pese a importância desses pequenos avanços nas décadas iniciais da República, predominam, nas práticas de ensino da história da época, a visão tradicional baseada no estudo do passado, com ênfase nos fatos políticos e feitos heróicos; a concepção de professor-transmissor e de aluno-receptor; a ausência de propostas que contribuam significativamente para superar o caráter livresco e memorístico da história escolar, dentre outros condicionamentos com os quais ainda nos debatemos hoje.

\section{A incorporação de fontes na história escolar:} permanências e mudanças

A licerçada nas novas orientações historiográficas e nas recentes transformações pedagógicas que emergem no cenário educativo 
Fontes históricas na sala de aula...

nacional, a história escolar vai, aos poucos, redesenhando suas concepções e proposições para a sala de aula. É bem verdadeque o ideário pedagógico e historiográfico avança a passos mais largos do que as ef etivas transformações que se operam no "chão da escola". N 0 entanto, incontáveis experiências são realizadas cotidianamente nos mais diversos e longínquos espaços escolares, ainda que protagonizadas isoladamente por iniciativa de professores.

$\mathrm{N}$ as políticas educacionais recentes, especialmente nos $\mathrm{Parâ}-$ metros Curriculares N acionais - Á rea de H istória (BRASI L, 1998) e no Programa N acional do Livro D idático - Á rea de H istória, identificamos inúmeros componentes de uma nova abordagem metodológica para o tratamento de fontes na história escolar. Para além do caráter ilustrativo e comprobatório que o uso escolar de fontes assumiu nos manuais didáticos em épocas passadas, as atuais políticas definem um novo ideário, que imprime centralidade à tarefa de relacionar o estudo de fontes históricas à construção do conhecimento.

Ao definir orientações e métodos didáticos para os anos finais do ensino fundamental, os PCN s apresentam um conjunto de treze situações didáticas, três das quais se referem especialmente a essas novas dinâmicas metodológicas, a saber:

D esenvolver atividades com diferentes fontes de informação (livros, jornais, revistas, filmes, fotografias, objetos, etc.) e confrontar dados e abordagens; trabalhar com documentos variados como sítios arqueológicos, edificações, plantas urbanas, mapas, instrumentos de trabalho, objetos cerimoniais e rituais, adornos, meios de comunicação, vestimentas, textos, imagens e filmes; ensinar procedimentos de pesquisa, consulta em fontes bibliográficas, organização das informações coletadas, como obter informações de documentos, como proceder em visitas e estudos do meio e como organizar resumos (BRA SI L, 1998, p. 77).

A perspectiva apontada pelos $\mathrm{PCN}$ s para o uso escolar de fontes históricas está alinhada com a historiografia recente, rompendo 
com a noção tradicional de fonte, originária do cientificismo do século XIX, concebida como "fonte d água" e entendida no sentido de que, "assim como das fontes d'água, das documentais jorrariam informações a serem usadas pelo historiador" (FUN ARI, 2006, p. 85). Tratando como documentos históricos "as mais diversas obras humanas produzidas nos mais diferentes contextos sociais e com objetivos variados" (BRASI L, 1998, p. 83), os PCN s apresentam diferentes exemplos, que compreendem tanto os registros escritos, quanto os expressos por meio de sons, gestos e imagens, a saber, filmes, músicas, gravuras, artefatos, edificações, fotografias, pinturas, esculturas, rituais, textos literários, poéticos e jornalísticos, anúncios, processos criminais, registros paroquiais, diários, arquivos familiares, dentre tantos outros não nomeados aqui.

Q uanto ao uso de tais documentos/ fontes em sala de aula, há importantes indicações metodológicas que preconizam o papel ativo do estudante nos procedimentos de compreensão e interpretação. M ais do que objetos ilustrativos, as fontes são trabalhadas no sentido de desenvolver habilidades de observação, problematização, análise, comparação, formulação de hipóteses, crítica, produção de sínteses, reconhecimento de diferenças e semelhanças, enfim, capacidades que favorecem a construção do conhecimento histórico numa perspectiva autônoma.

O s procedimentos a serem desenvolvidos no tratamento de fontes em sala de aula requerem competências específicas do professor de história na organização do trabalho pedagógico, como pode ser verificado na seguinte citação:

Com o propósito didático, o professor pode solicitar suas primeiras impressões, instigá-los no questionamento, confrontar com informações divergentes, destacar detalhes, socializar observações e criar um momento para que possam comparar suas idéias iniciais com as novas interpretações conquistadas ao longo do trabalho de análise. Com atenção e perspicácia, podem ser observadas e colhidas informações nos detalhes: 
Fontes históricas na sala de aula...

\begin{abstract}
fatos, estéticas, conceitos, sentidos etc. É possível pesquisar informações sobre o documento em fontes externas (autoria, contexto da obra, estilo etc.) e confrontar eventos históricos identificados na fonte estudada a eventos de outras épocas, quanto a semelhanças e/ ou diferenças e relações de continuidade e/ ou descontinuidade. Q uando o professor considerar necessário, pode ser feita a pesquisa da trajetória histórica de preservação, conservação e difusão do documento. É importante que o trabalho envolva observações, descrições, análises, pesquisas, relações e interpretações e, no final, aconteça um momento de retorno ao documento, para que os alunos comparem as novas informações - o seu "novo olhar" - com suas apreensões iniciais e reflitam sobre problemáticas históricas a ele relacionadas (BRASI L, 1998, p. 86-7).
\end{abstract}

$\mathrm{N}$ a mesma linha dos $\mathrm{PCN}$ s, a atual política nacional de livro didático, capitaneada pelo M inistério da E ducação por meio do Programa $\mathrm{N}$ acional do Livro D idático (PN LD ), reconhece a importância do trabalho com fontes históricas na sala de aula, razão pela qual estabelece no edital de convocação para inscrição no processo de avaliação e seleção de obras didáticas (BRASIL, 2008) critérios rigorosos quanto à condução metodológica nos livros que se candidatam a esta avaliação governamental, com vistas a integrar o guia de livros didáticos para os anos finais do ensino fundamental e a subseqüente distribuição nas escolas públicas de todo o país.

D entre os muitos critérios apresentados no edital enfatizam-se "a apresentação e efetiva discussão de fontes históricas, incorporandoas ao texto didático e mobilizando-as para a construção do conhecimento", entendendo tais ações como "imprescindíveis para que o livro didático introduza os alunos na metodologia própria da $H$ istória, levando-os à compreensão de como se produz esse conhecimento" (BRASI L, 2008, p. 49). D a mesma forma, a apresentação de imagens e de quaisquer recursos visuais precisa se constituir em "recursos intrínsecos à problematização e à compreensão dos conteúdos históricos", fazendo parte dos objetivos do texto, não 
apenas da sua ilustração. Para tanto, as imagens devem ser devidamente contextualizadas, com legendas que permitam a identificação temporal e espacial da fonte, contendo no mínimo alguns dados, como época de produção, autoria, natureza e créditos.

As propostas de incorporar na sala de aula o trabalho com fontes históricas, na perspectiva apresentada pelos PCN sepelo PN LD, fundamentam-se na idéia de superação dos métodos memorísticos, próprios de uma concepção histórica que privilegia a erudição em detrimento da possibilidade de produção de conhecimento histórico escolar. Essa tese vem sendo defendida também por inúmeros pesquisadores interessados no campo da aprendizagem histórica, sendo justificada pelo argumento de que "é imprescindível que a história seja trabalhada nas aulas incorporando toda sua coerência interna e oferecendo chaves para 0 acesso a sua estrutura como conhecimento científico do passado" (PRATS, 2006, p. 204); ou ainda pelo argumento de que 0 uso de documentos pode favorecer o desenvolvimento do pensamento histórico, facilitando "a compreensão do processo de produção do conhecimento histórico pelo entendimento de que os vestígios do passado se encontram em diferentes lugares, fazem parte da memória social e precisam ser preservados como patrimônio da humanidade" (BITTE N COURT, 2004, p. 333).

A prender a historiar ou aprender o ofício dos historiadores não significa almejar que o estudante se torne um pequeno historiador, até porque as finalidades do trabalho do historiador, ao produzir conhecimento histórico, são distintas das finalidades do trabalho do professor ao ensinar história. 0 historiador toma as fontes como matéria-prima para desenvolver o seu ofício e, como especialista, reconhece todo o contexto de produção antes mesmo de delimitá-las para o seu estudo, ao passo que, como afirma Bittencourt (2004, p. 329), "os jovens e as crianças estão aprendendo história e não dominam o contexto histórico em que o documento foi produzido". A ssim, ensinar o ofício do historiador consistiria em construir com os alunos uma bagagem conceitual e metodológica que lhes permitisse 
compreender (e utilizar em certo nível de complexidade) os instrumentos e procedimentos básicos da produção do conhecimento histórico.

Retornando aos PCN s, encontramos outros argumentos favoráveis ao trabalho pedagógico voltado para o domínio dos procedimentos de pesquisa na escola, tais como: a) ampliar conhecimentos, capacidades e atitudes de autonomia dos estudantes; b) localizar, relacionar e comparar informações; desenvolver domínios lingüísticos; identificar idéias de diferentes autores, suas contradições e complementaridades; selecionar, tomar decisões e socializar informações diversas (BRASIL, 1998, p. 82).

A pós transitar pelos aspectos históricos e conceituais da história escolar no que se refere à incorporação e à utilização de fontes históricas, vejamos como o tema se configura na atual produção nacional de livros didáticos de história. D entre os caminhos metodológicos possíveis para a identificação das obras, tomamos como fonte principal o G uia de L ivros D idáticos PN LD 2008 - Área de $\mathrm{H}$ istória, referente aos anos finais do ensino fundamental. $\mathrm{N}$ a apresentação de uma análise geral das dezenove coleções aprovadas para compor o guia, constam elementos relativos à incorporação de fontes históricas e documentos, sendo aqueles manifestados nos seguintes termos:

Com efeito, exploram-se as fontes com a intenção de levar 0 aluno a percebê-las como uma produção histórica, que se deve localizar no tempo e no espaço, sendo lidas como uma versão dos acontecimentos produzidos por determinados sujeitos históricos. D esta forma, enfatiza-se 0 aspecto seletivo, parcial e provisório do conhecimento histórico. Compreende-se, então, a atenção dada à leitura das fontes, levando 0 aluno ao reconhecimento de suas condições de produção (BRASIL, 2007, p. 23).

A despeito dessa manifestação positiva, verifica-se que, do conjunto das dezenove coleções apresentadas no guia, apenas cinco 
receberam o conceito ótimo no item "Fontes históricas/ documentos"; dez, conceito bom; três, conceito suficiente e uma coleção não é mencionada nesta classificação. ${ }^{2}$ D entre as cinco bem avaliadas neste critério, encontram-se $H$ istória em projetos, com avaliação máxima (ótimo) também nos demais critérios, totalizando dez pontos; Projeto A raribá, com oito pontos de avaliação máxima no total de critérios; $H$ istoriar: fazendo, contando e narrando a história, totalizando sete pontos; Saber e fazer história, com seis pontos, e H istória, conceitos e procedimentos, que só obteve classificação máxima neste critério. ${ }^{3}$

Para finalizar o presente estudo, focalizaremos uma única obra didática, com o intuito de aprofundar nela a compreensão do que está sendo considerado uma proposta de trabalho exemplar com fontes e documentos históricos. Trata-se daquela que obteve a máxima pontuação no $\mathrm{G}$ uia, intitulada $\mathrm{H}$ istória em projetos, de autoria de Conceição Oliveira, Carla Miucci Ferraresi e Andrea Paula dos Santos, publicada pela E ditora Ática no ano de 2007. A apresentação da coleção no G uia de L ivros D idáticos PN L D 2008 enfatiza que tal obra "incorpora importantes elementos da renovação historiográfica, em particular a utilização de um conjunto significativo de imagens, trabalhadas como fonte de conhecimento histórico" (BRASIL, 2007, p. 59). N a própria coleção, há uma apresentação, escrita por Leandro K arnal, que também destaca positivamente os aspectos relativos às fontes e documentos históricos, como verificamos nos seguintes trechos: "E ncontrei aqui uma saudável preocupação com o envolvimento do/ a aluno/ a, com a sedução afetiva do/ a jovem leitor/ a. Há figuras trabalhadas de fato e não apenas como ilustração (...)" (K ARN AL, 2007, p. 3).

Para fins de delimitação do estudo, trataremos aqui tão-somente do livro referente à $8^{a}$ série/ 9 o ano do ensino fundamental, que totaliza 288 páginas, organizadas em cinco unidades, contendo de três a cinco capítulos cada uma, chegando ao número de vinte. A primeira unidade contém cinco capítulos e apresenta 98 documentos históricos; a segunda é organizada em três capítulos, com 63 documentos; a terceira possui três capítulos e 54 documentos; 
Fontes históricas na sala de aula...

a quarta unidade é composta de quatro capítulos e 65 documentos; a quinta e última unidade comporta cinco capítulos, com 97 documentos. Portanto, a coleção oferece para análise do estudante 377 documentos históricos. 0 tema geral deste livro é "A encruzilhada dos mundos, consertos e desconsertos nos séculos XX e XXI", (0) trabalhando conhecimentos da história do Brasil e mundial numa ${ }_{4}$ perspectiva integrada.

Como enfatiza $K$ arnal na apresentação da coleção, as autoras trabalham com uma variedade de documentos, sem se restringir àqueles convencionais, que estão presentes em todas as coleções, a exemplo do quadro da Primeira missa no B rasil (V ictor M eirelles, 1860), ${ }_{1}^{4}$ ou da charge da D enúncia ao voto de cabresto (Storni, 1927). Constam no livro fontes impressas, tais como trechos de textos jornalísticos, literários, acadêmicos, discursos, anúncios, revistas, livretos, gibis, poemas, letras de música, cordel, paródias, correspondências, depoimentos orais, dentre outros; fontes iconográficas, tais como pinturas, charges, caricaturas, fotografias, propagandas, cartazes etc.; fontes materiais, como artefatos, edificações, esculturas, trajes, paisagens, vistas; outros documentos, como mapas antigos e atuais, gráficos, tabelas, dentre outros. Ao estabelecer propostas de trabal ho interativas, nas quais os estudantes possam não só dialogar com os documentos em si, mas, sobretudo, trabalhar com diferentes tipos de fontes sobre o mesmo tema, o livro oferece contribuições para o desenvolvimento do pensamento histórico, demonstrando que os vestígios do passado encontram-se em muitos lugares, tanto no discurso de um governante quanto num cartaz de propaganda ou numa fotografia.

\section{Considerações finais}

A utilização de documentos no ensino da história, como perce bemos, não é uma proposta recente na trajetória escolar. Há registros durante todo o século $X X$ sobre sua incorporação nos manuais e livros didáticos, bem como a defesa de seu uso em sala de aula, na 
literatura de cunho pedagógico. 0 que mudou nas últimas décadas foi 0 entendimento quanto às suas finalidades nas aulas de história. $\mathrm{N}$ a atual compreensão do tema, é imprescindível o trabalho do professor e do aluno na problematização e significação dos documentos, utilizando-os de modo a extrapolar meras funções de ilustração, motivação, informação ou prova, ainda que estas possam ter relativa importância. 0 desafio é, tomando os documentos como fontes, entendê-los como marcas do passado, portadores de indícios sobre situações vividas, que contêm saberes e significados que não estão dados, mas que precisam ser construídos com base em olhares, indagações e problemáticas colocadas pelo trabalho ativo e construtivo dos alunos, mediados pelo trabalho do professor.

N esse desafio, estão implicados alguns pressupostos que precisam ser considerados e outros que devem ser superados, dentre os quais: 1) para que o trabalho com fontes na sala de aula da educação básica se efetive na perspectiva da produção de conhecimento histórico, necessitamos redimensionar os cursos de formação de professores dehistória, de modo a possibilitar que os acadêmicos vivenciem, ainda no seu percurso formativo, experiências criativas e consistentes no uso de fontes, do contrário eles reproduzirão o conteudismo/ verbalismo das aulas da licenciatura; 2) a compreensão de que a pesquisa e o ensino são dimensões de um mesmo fazer historiográfico/ pedagógico e que aprender história pressupõe compreender os mecanismos e condições de sua produção, guardando as especificidades de cada nível de escolarização; 3) a necessidade de repensar antigas dicotomias colocadas para o ensino da história escolar, tais como conteúdos $X$ métodos, história-narrativa $X$ história-problema, superando abordagens informativas cuja pretensão é esgotar o estudo de todas as sociedades, de todas as épocas e lugares. E nsinar/ aprender história na perspectiva da produção de conhecimentos exige fazer opções (teóricas, metodológicas, historiográficas) e estabelecer recortes (temáticos, temporais, espaciais, conceituais). 
E m certa medida, essas questões permeiam a agenda do dia no debate acadêmico e escolar. São preocupações que teimam em permanecer no ideário, sem penetrar ef etivamente nos fazeres pedagógicos, ou serem assumidas nos projetos pedagógicos escolares no âmbito da educação básica, senão como experiências isoladas bem-sucedidas, protagonizadas pela iniciativa e opção pessoal dos professores. M uitas inovações metodológicas, a despeito das intenções com que foram concebidas, conseguiram tão-somente dar um caráter mais lúdico e atraente à história escolar, sem necessariamente desafiar os conteúdos selecionados, a perspectiva cronológico-linear, a narrativa protagonizada pelo professor e o papel pouco ativo do estudante, substituindo os ouvidos pelos olhos, na modesta perspectiva que Serrano já denunciava na década de 1930. A pesar dos avanços observados, muito ainda há por ser feito, tarefa que envolve professores da educação básica, estudantes, professores formadores, políticas públicas e sociedade. E nsinar/ aprender história de modo a problematizar a realidade, a percebê-la como uma construção histórica, não como um dado natural, e, com base nisso, fazer escoIhas pessoais, profissionais, sociais é um desafio ainda presente.

$\mathrm{H}$ istorical sources in the classroom: a possibility for the production of historical knowledge at school?

Abstract: The incorporation and use of historical sources in History classes constitute a guideline of the current discussions at schools and universities. It has been discussed about (1) those sources as possibilities of overcoming the lessons based on tables of contents, and (2) its potentialities as an instrument for the production of historical knowledge in basic education. This study presents the contextualization of the problem by identifying in the old and new school books, as well as in the public policies adopted through the official documents Parâmetros Curriculares $\mathrm{N}$ acionais (PCN s) and official program Programa N acional do L ivro D idáti$\omega(P N ~ L D)$, the proposed and accomplished uses of sources as an alternativefor the production of historical knowledge in the scope of $\mathrm{H}$ istory teaching at school, finding changes and remaining characteristics found there.

Keywords: history teaching - historical source- knowledge production 
Flávia Eloisa Caimi

\section{N otas}

${ }^{1}$ D entre as principais obras de Jonathas Serrano, destacam-se M ethodologia da história na aula primária (1917) A E scola N ova. U ma palavra serena, em um debateapaix onado (1932) eC omo seensina a história (1935), dirigidas a professores, além de expressivos manuais didáticos como E pítomedehistória universal (1915) e H istória do B rasil (1931).

${ }^{2}$ Segundo constano G uia deL ivros D idáticos PN L D 2008 - Á rea de H istória, "a coleção poderia ser consideradaótima, quando atingisse plenamente o que estivesse estabelecido; boa, quando alcançasse o queestava previsto em quase todos os pontos do item; suficiente, quando conseguisse apenas em parte ou de uma forma mínima o quefosse exigido; ou não, quando não atendesse o mínimo necessário para se considerar 0 ponto avaliado, ou ainda, inexistisse o componentesolicitado" (BRA SI L, 2007, p.16). ${ }^{3}$ O s dez critérios avaliados são: 1) concepção de história; 2) conhecimentos históricos; 3) fontes históricas/ documentos; 4) imagens; 5) metodologia de ensino-aprendizagem; 6) capacidades ehabilidades; 7) atividades e exercícios; 8) construção dacidadania; 9) manual do professor; 10) editoração e aspectos visuais (BRA SI L , 2007).

${ }^{4}$ E m geral, esta obra - assim como 0 grito do I piranga, de Pedro A mérico, e tantas outras - tem sido lida e entendida pelos estudantes como uma fotografia do evento, contendo em si a prova de que aquilo realmente aconteceu, enão como uma representação artística produzida décadas depois, em determinado contexto e segundo determinados interesses.

\section{Referências}

BRASIL. Secretaria de E ducação Fundamental. Parâmetros curriculares nacionais: história. Secretaria de E ducação F undamental. Brasília: M E C / SE F, 1998.

BRASIL. M inistério da Educação. Fundo $\mathrm{N}$ acional de Desenvolvimento da E ducação. Secretaria de E ducação Básica. Programa N acional do Livro D idático. E dital de convocação para inscrição no processo de avaliação eseleção de obras didáticas a serem incluídas no guia de livros didáticos para os anos finais do ensino fundamental. PN LD / 2008.

BRASI L. M inistério daE ducação. G uia delivros didáticos PN L D 2008: H istória. Brasília: MEC, 2007. (A nos Finais do Ensino Fundamental).

BITTE N CO URT, Circe M. F. E nsino de história: fundamentos e métodos. São Paulo: Cortez, 2004.

CAIMI, Flávia E loísa. A prendendo a ser professor de história. Passo Fundo: Editora U niversidade de Passo Fundo, 2008. 
Fontes históricas na sala de aula...

FICO, Carlos. Algumas anotações sobre historiografia, teoria e método no Brasil dos anos 1990. In: G UAZE LLI, Carlos A.B et al. Q uestôes de teoria emetodologia da história. Porto A legre: E ditora da U niversidade/ U FRG S, 2000. p. 27-40.

FO N SE CA, Thaís N ívia de Lima e. H istória e ensino de história. Belo H orizonte: Autêntica, 2003.

FU N A RI, Pedro Paulo. Os historiadores e a cultura material. In: PIN SK Y, C. B. Fontes históricas. 2. ed. São Paulo: Contexto, 2006.

GOMES, Ângela de Castro. A reflexão teórico-metodológica dos historiadores brasileiros: contribuições para pensar a nossa história. I n: G UAZE LLI, Carlos A.B. et al. Q uestôes deteoria emetodologia da história. Porto A legre: E ditora da U niversidade/ UFRGS, 2000. p. 19-26.

MATTOS, SelmaR. 0 B rasil em liçộs: a história como disciplina escolar em Joaquim Manoel de Macedo. Rio de Janeiro: Access, 2000.

O LIVEIRA, M.C.C.; FERRARESI , C.M.; SANTOS, A.P. H istória em projetos. 8 a série. São Paulo: E ditoraÁtica, 2007.

PO M BO, Rocha. N ossa pátria. 79. ed. São Paulo: Companhia M elhoramentos, s/ d.

PRATS, Joaquin. Ensinar históriano contexto das ciências sociais: princípios básicos. E ducar. Curitiba: E ditoraU F PR, n. esp., p. 191-218, 2006.

RO D RIG UES, José H onório. A pesquisa histórica no Brasil. 4. ed. São Paulo: Cia. E ditora $\mathrm{N}$ acional, 1982.

SAM A RA, E ni de M esquita; TUPY, Ismênia S. Silveira. H istória edocumento emetodologia depesquisa. Belo H orizonte: A utêntica, 2007.

SERRAN O, Jonathas. A E scola N ova. Uma palavra serena, em um debate apaixonado. Rio de Janeiro: Schmidt, 1932, p. 115.

Āives, $19 \overline{3}$.

. E pítome de história universal. 17. ed. Rio de Janeiro: Livraria F rancisco

SCH MIDT, M ariaA uxiliadora. História com Pedagogia: a contribuição da obra de Jonathas Serrano na construção do código disciplinar da H istória no Brasil. R evista B rasileira deH istória, São Paulo, v. 24, n. 48, p.189-211, 2004.

VITÓ RIA, J.P.; ADAMI, F. H istória do B rasil. Primeira série ginasial. São Paulo: Livraria Franscisco Alves; Paulo de Azevedo, 1955.

Recebido em 24/08/ 2008

A provado em 06/ 10/ 2008

Anos 90, Porto Alegre, v. 15, n. 28, p.129-150, dez. 2008 